\title{
Compact Wideband Dual-Polarized Microstrip Patch Antenna
}

\author{
K. Rambabu*, M. Alam, J. Bornemann and M. A. Stuchly \\ Department of Electrical and Computer Engineering \\ University of Victoria, Victoria, B.C., Canada V8W 3P6
}

\section{INTRODUCTION}

Bandwidth enhancement by multiple resonances is a widely used technique for microstrip patch antennas. There are numerous methods to couple multiple resonances. Examples include coupled patches [1], patches with slots (e.g. U- and E-shaped) [2], [3], stacked patches [4], and patches with aperture-coupled feeds [5]. In some personal wireless communications systems, such as used for triple band option, more than 30 percent of the operating bandwidth is required. Bandwidth in excess of 70 percent can be achieved with aperture-coupled stacked patches [6]. However, such configurations occupy considerable space and are not always acceptable for integration with other circuitry. For handheld wireless systems, a compact single patch on moderately thick substrate is preferred. For such antenna, achieving more than 25 percent bandwidth and moderate gain presents a challenge.

Therefore, in this paper, we present a single-layer microstrip patch antenna on a relatively thin substrate. The design employs multiple resonances without significantly enlarging the size. It achieves 54 percent VSWR and 40 percent gain bandwith for $\operatorname{VSWR}<2$ and $\mathrm{G}>2 \mathrm{dBi}$, respectively.

\section{PRINCIPLE OF OPERATION AND DESIGN}

Three square patches are overlapped along their diagonals as shown in Fig 1. The dimensions of the patches are $\left(\mathrm{W}_{1} \times \mathrm{W}_{1}\right),\left(\mathrm{W}_{2} \times \mathrm{W}_{2}\right)$ and $\left(\mathrm{W}_{3} \times \mathrm{W}_{3}\right)$, respectively. $\mathrm{S}_{1}$ and $\mathrm{S}_{3}$ indicate the overlapping dimensions of the patches. The structure has five different resonant lengths as follows:

$$
\begin{aligned}
& l_{1}=W_{2}+\left(W_{3}-S_{3}\right)+2 \Delta l_{1} \\
& l_{2}=W_{2}+\left(W_{1}-S_{1}\right)+2 \Delta l_{2} \\
& l_{3}=W_{2}+2 \Delta l_{3} \\
& l_{4}=2 W_{1}-\left(W_{1}-S_{1}\right)+2 \Delta l_{4} \\
& l_{5}=2 W_{3}-\left(W_{3}-S_{3}\right)+2 \Delta l_{5}
\end{aligned}
$$

The increments to the lengths, $\Delta l_{1}, \Delta l_{2}, \Delta l_{3}, \Delta l_{4}$, and $\Delta l_{5}$, are due to the fringing fields and can be computed from formulae given in [7]. As an example, an antenna with the following dimensions was designed: three square patches of dimensions $(13.5 \times 13.5) \mathrm{mm},(7.5 \times 7.5) \mathrm{mm}$ and $(7.1 \times 7.1) \mathrm{mm}$ with 
overlapping dimensions $S_{1}=6.4 \mathrm{~mm}$ and $S_{3}=4.6 \mathrm{~mm}$; a dielectric substrate of relative permittivity $\varepsilon_{\mathrm{r}}=2.35$ and thickness $h=3.175 \mathrm{~mm}$ was used.

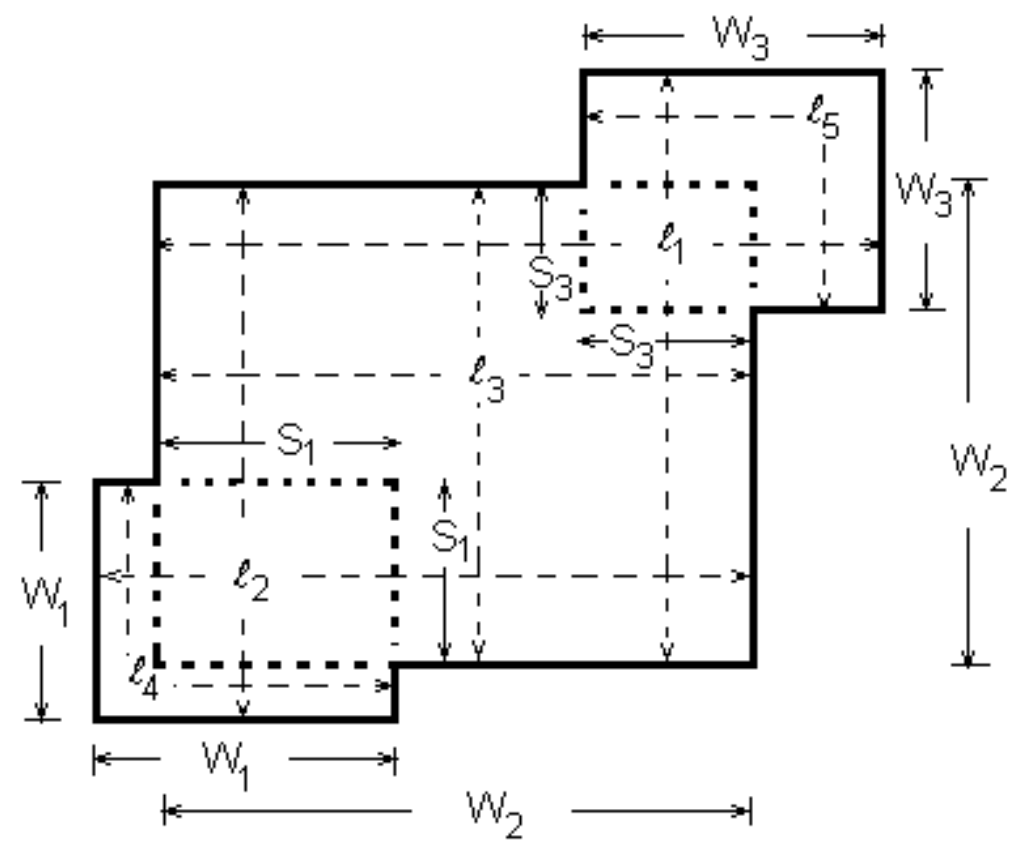

Fig.1 Geometry of the multi-resonance broadband patch.

\section{NUMERICAL MODELING}

The commercial software package IE3D was used to model the antenna. Resonant frequencies computed with IE3D and with equation (1) are compared in Table I. Good agreement is apparent. The differences are attributed to the inductance of the feed probe which was included in the numerical modeling.

Table I: Comparison of resonant frequencies

\begin{tabular}{|c|c|c|c|c|c|}
\hline $\begin{array}{c}\text { Resonant } \\
\text { length }\end{array}$ & $\begin{array}{c}\text { Physical } \\
\text { dimension } \\
(\mathrm{mm})\end{array}$ & $\begin{array}{c}\text { Fringing } \\
\text { field } \\
\text { length } \\
(\mathrm{mm})\end{array}$ & $\begin{array}{c}\text { Total } \\
\text { length } \\
(\mathrm{mm})\end{array}$ & $\begin{array}{c}\text { Calculated } \\
\text { resonance } \\
\text { frequency } \\
(\mathrm{GHz})\end{array}$ & $\begin{array}{c}\text { Resonance } \\
\text { from IE3D } \\
(\mathrm{GHz})\end{array}$ \\
\hline $1_{1}$ & 16 & 2.63 & 21.26 & 4.98 & 4.7 \\
\hline $1_{2}$ & 14.6 & 2.45 & 19.5 & 5.4 & 5.1 \\
\hline $1_{3}$ & 13.5 & 2.33 & 18.16 & 5.84 & 5.7 \\
\hline $1_{4}$ & $(7.5 \times 2)-1.1$ & 1.7 & 17.3 & 6.2 & 6.7 \\
\hline $1_{5}$ & $(7.1 \times 2)-2.5$ & 1.65 & 14.8 & 7.2 & 7.4 \\
\hline
\end{tabular}

The current distribution on the patch is shown in Figure 2. In the extreme edges, it illustrates the curved paths along the mean dimension $l_{4}$ and $l_{5}$, and thus confirms the corresponding resonant frequencies given by equation (1). The dual-polarized behavior is explained as follows: At resonance frequencies $f_{1}, f_{2}$ and $f_{3}$, the antenna has two radiating strips perpendicular to each other, which radiate in 
vertical and horizontal polarizations (c.f. Fig. 1). At resonance frequencies $f_{4}$ and $f_{5}$, the radiating strip has a bend at the center, and its radiation is due to two perpendicular edges, which provides dual polarization.

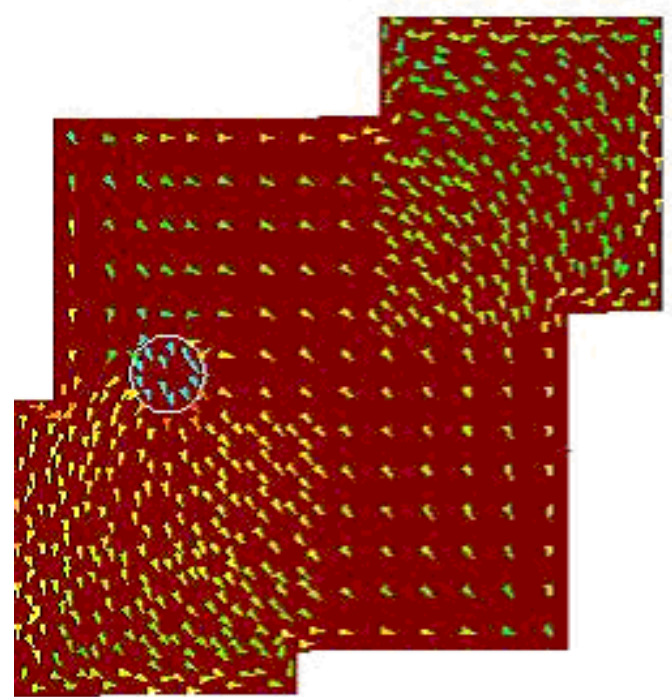

Fig 2. Current distribution on the patch surface and location of the feed.

Figures 3 and 4 illustrate the VSWR and gain of the antenna. Due to the fact that the radiating apertures of the two edge patches are relatively smaller compared to those of the main patch, the gain decreases at higher frequencies. It is expected that the gain can be increased by adding periodic elements, e.g., [8].

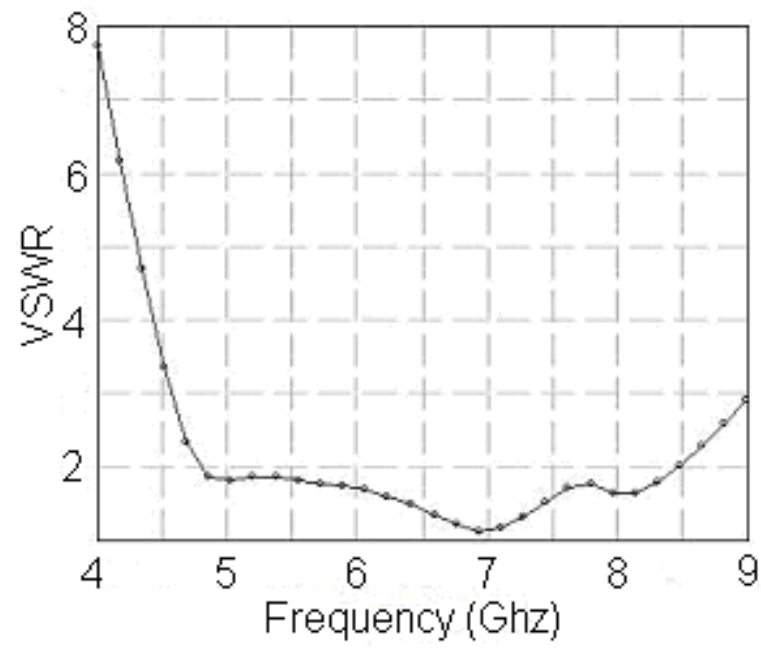

Fig. 3 VSWR of the antenna.

\section{CONCLUSIONS}

A compact dual-polarized microstrip patch antenna has been designed, and formulas for its preliminary design have been provided. The arrangement of 
overlapping patches and their associated resonant frequencies are verified by a commercial field solver. The structure is easily fabricated on a single-layer and relatively thin substrate for applications in hand-held devices. The design guidelines are straightforward so that the antenna can easily be used in other frequency bands and with different substrate materials. Furthermore, the antenna gain can be increased by adding periodic elements.

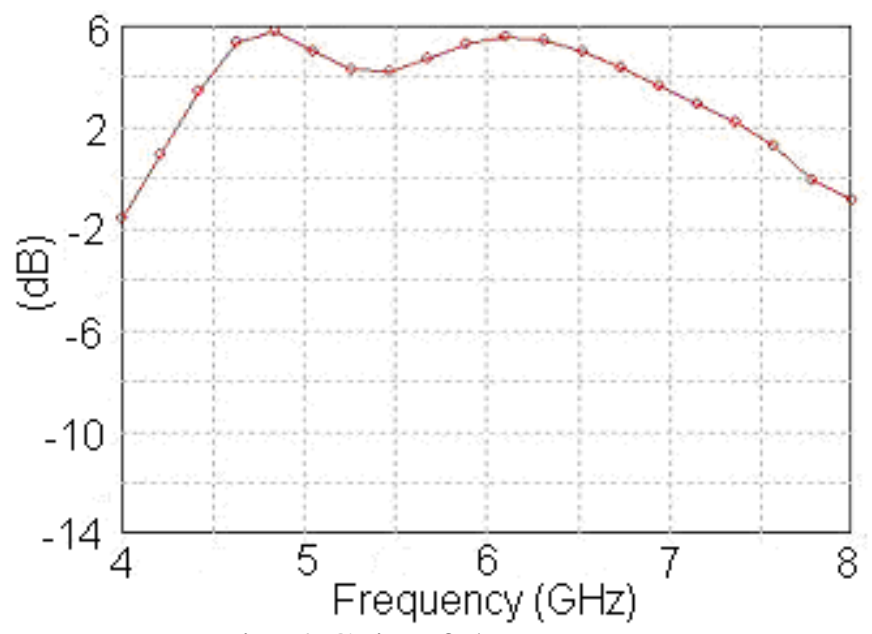

Fig. 4 Gain of the antenna.

\section{REFERENCES}

[1] G. Kumar and K.C. Gupta, "Directly coupled multiple resonator wideband microstrip antennas", IEEE Trans. Antennas Propagat., Vol. 33, pp. 588- 593, June 1985.

[2] T. Huynh and K.F. Lee, "Single-layer single patch wideband microstrip antenna" Electronics Lett., Vol.31, pp. 1310-1312, Aug. 1995.

[3] F. Yang, X.X. Zhang, X. Ye and Y. Rahmat-Samii, "Wide-band E-shaped Patch Antennas for wireless communications" IEEE Trans. Antennas Propagat., Vol.49, pp. 1094-1100, July 2001.

[4] S.A. Long and D.M. Walton, "A dual-frequency stacked circular-disc antenna", IEEE Trans. Antennas Propagat., Vol. 27, pp. 270- 273, Mar. 1979.

[5] D.M. Pozar, "A microstrip antenna aperture coupled to a microstrip lines", Electronics Lett., Vol. 21, Jan. 1985.

[6] R.B. Waterhouse, Microstrip Patch Antennas - A Designers Guide, Chapter 3, Kluwer Academic Publishers, 2003.

[7] K.C. Gupta, R. Garg, I. Bahl and P. Bhartia, Microstrip Lines and Slotlines, pp. 180-183, Second ed., Artech House, 1996.

[8] M. Rahman and M.A. Stuchly, "Circularly polarized patch antenna with periodic structure," IEE Proc.-Microw. Antennas Propag., Vol. 149, No. 3, pp. 141-146, June 2002. 